\section{EXPERIMENTAL RESEARCH ON THE CONCEPT OF USING AN AUTONOMOUS TRANSPORT MODULE FOR TRANSPORT FROM THE SEABED}

DOI 10.2478/ntpe-2018-0033

\author{
Dr. Wiktor Filipek, Dr. Krzysztof Broda \\ AGH University of Science and Technology, Poland
}

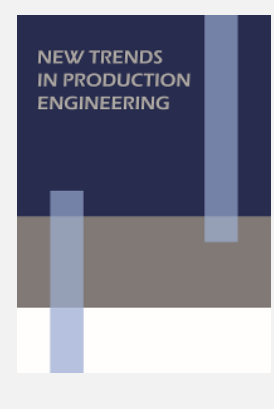

2018

Volume 1

Issue 1

pp. $267-275$

\begin{abstract}
The great interest in the exploitation of sea deposits has in recent years resulted in the creation of many consortia conducting research on various methods of mining and transport to the surface. Exploitation of the shelf areas of crude oil and gas as well as solid minerals is successfully carried out in many places around the world using various methods. More and more often, however, we want to obtain natural resources found at great depths such as polymetallic nodules and massive polymetallic sulphides. This puts much greater demands on scientists and engineers. Unfortunately, solutions developed so far are characterized by high energy consumption. For several years, the authors have been researching new concepts of transport from the seabed. In previous years the authors presented theoretical research results of using a new method involving the use of pyrotechnic materials as a source of energy in transport from the seabed from large depths and experimental ones with the use of potassium nitrate and ammonium nitrate in a controlled pyrotechnic reaction and they compared three conceptions of transport of dredge spoil from the point of view of energy demand. This publication presents the results of the continuation of research, this time on the concept of building an autonomous transport module and its operating principles. The construction of the laboratory stand and the way of conducting experiments are discussed. The results of experimental research are presented, which confirm the possibility of using the discussed concept in transport from the seabed.
\end{abstract}

Keywords: marine mining, transport from great depths, autonomous transport module

\title{
INTRODUCTION
}

In recent years, due to the intensive mining and, consequently, the depletion of land deposits of many minerals, the attention of investors and scientists has turned towards sea deposits. Exploitation of the shelf areas of crude oil and gas as well as solid minerals is successfully carried out in many places around the world using various methods (Karlic, 1984, Depowski et al., 1998). However, reaching for natural resources lying at great depths puts much greater demands on scientists and engineers.

The interest in the occurrence of polymetallic nodules and massive polymetallic sulphides (SMS) at great depths and huge areas of the seabed (Sharma, 2017; SPC, 2013) resulted in the formation of many consortia that conduct research on various methods of mining and transport to the surface. Unfortunately, they are characterized by high energy consumption.

For several years, the authors have been researching new concepts of transport from the seabed. In previous years (Filipek and Broda, 2016, 2017) the authors presented theoretical research results of using a new method involving the use of pyrotechnic materials as a source of energy in transport from the seabed from large depths and experimental ones with the use of potassium nitrate and ammonium nitrate in a controlled pyrotechnic reaction and they compared three concepts of transport of dredge spoil from the point of view of energy demand. This publication presents the results of the continuation of research - this time on the concept of building a transport module and an experimental confirmation of the possibility of its use in transport from the seabed. 


\section{THE CONCEPT OF THE TRANSPORT MODULE}

Starting to research and build an experimental laboratory model, the Authors decided primarily to focus on the simplicity of the structure (no electronic parts - only mechanical ones) and the use of physical phenomena accompanying the dipping and ascension processes and chemical reactions. The reaction of $\mathrm{CaC}_{2}$ calcium carbide (Morrison and Boyd, 1997; Kaczyński and Czaplicki, 1997) with water was used as a source of energy. The choice of this substance (substance B, Fig. 1) results from the fact that the pressure range used at the laboratory stand did not exceed 2.5 bar, so that no "strong" energy sources were needed as previously tested. In practical use, the authors predict the use of other energy sources, due to problems with the chemical stability of $\mathrm{C}_{2} \mathrm{H}_{2}$ acetylene resulting from the reaction of carbide with water and being the "source of energy" in the analyzed solution. Nevertheless, for the purpose of testing the concept of correct operation of the autonomous transport module, the authors concluded that the adopted energy source for experimental research is sufficient.

The concept of the transport module is shown in Fig. 1. It is made up of three main parts: a reaction chamber, a working chamber and a control chamber. The reaction chamber is connected to the working chamber by a tube (tube 1), where the exchange of fluids between the chambers - water (from the working chamber to the reaction chamber) and gaseous reaction products (from the reaction chamber to the working chamber) takes place. At the bottom of the working chamber there are openings allowing for the circulation of water between the working chamber and the external environment.

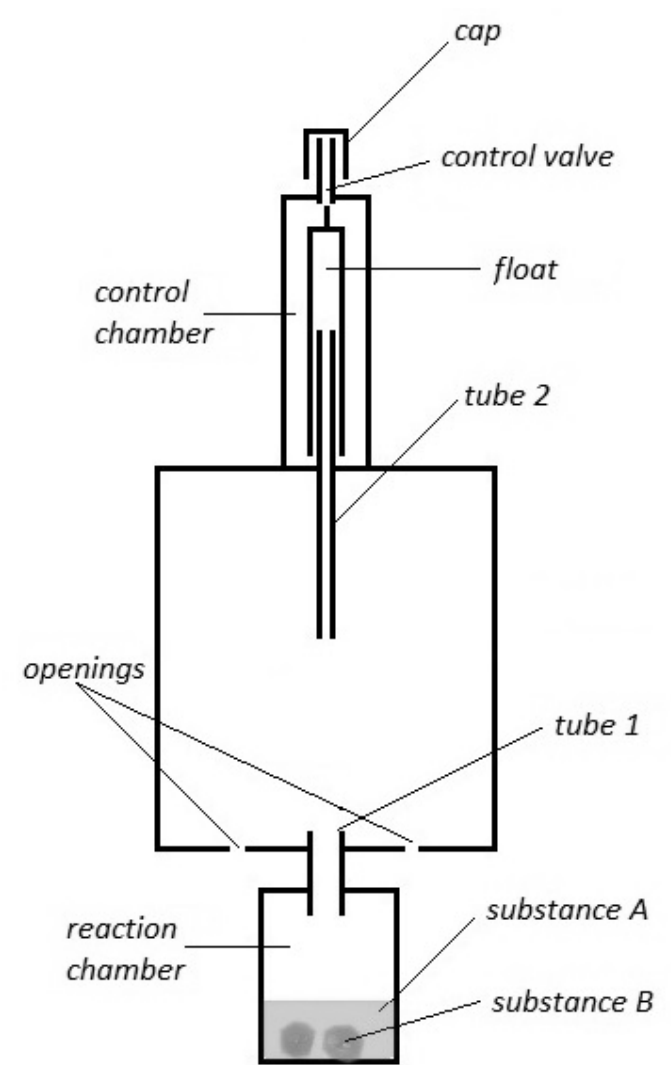

Fig. 1. Diagram of the construction of the transport module.

The working chamber is connected to the control chamber of tube 2, through which, depending on the stage of the transport process, either air or water flows. In the control chamber there is a float that closes it (with sufficient buoyancy force when the control chamber is flooded with water and a float filled with air) or opens creating the so-called control valve. Above the opening at the top of the control chamber there is a cap. All modules have been connected to each other in a way that they can be disconnected, cleaned and filled, if necessary, and then assembled together. Since in most experiments (as well as later during the actual operation of such transport modules) we want to delay the start of the substance $B$ 
reaction with water, we used substance $A$ neutral to substance $B$, but soluble in water. However, this process of dissolution gives us the necessary time to properly operate the transport module. Having developed the concept and model of the transport module, we have built an experimental stand.

\section{RESEARCH STAND}

The test stand shown in Fig. 2 is used to test the principle of operation of our transport module. Glass pipe 1 models the aquatic environment. Bottom and top pipes are tightly closed so that the system can work under elevated pressure. At the bottom of the pipe there are two valves 2 and 3 . Valve 2 is connected to the water supply pipe, with the possibility of working at elevated pressure. After the experiments are completed, the tank (pipe) is also emptied through this valve. The valve 3 , additionally equipped with a distributor, enables the connection of various measuring instruments, among others differential manometer 4 for accurate pressure measurement. In the pipe we place the model of the transport module 7. For the coarse measurement of the pressure in the measurement system during the filling and duration of the experiment, a pressure gauge 5 fixed in the upper tube cover is used. The valve 6 is connected with a pipe with an air pump, by means of which the pressure in pipe 1 can be adjusted. Valve 6 also serves to lower the pressure after the experiment. A series of experiments were carried out in such a constructed research stand.

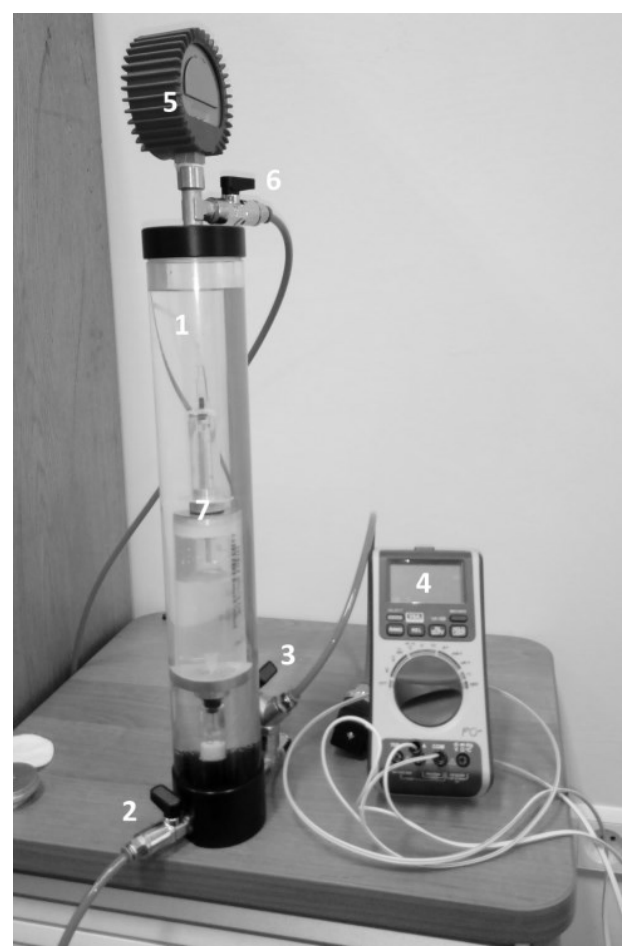

Fig. 2. Experimental stand for research on the concept of autonomous use transport module for transport from the seabed.

\section{EXPERIMENTAL RESEARCH}

On entering the research, the water supply pipe was connected to the valve 2 and the pipe was filled with water to a predetermined level with the upper lid unscrewed. Then, a transport module model - first with an empty reaction chamber - was inserted from the top to investigate the behavior of the device without any reaction. The purpose of these experiments was to determine the optimal length $L_{s}$ of tube 2 . It depended on appropriately chosen length whether the module would immerse. On the other hand, depending on the immersion rate $v_{o}$, the closure of the control valve was correct when the control chamber was being immersed. The $D_{s}$ diameter of the tube 2, the fluid exchange area between the working chamber and the A environment, the minimum immersion volume of the $V_{s z}$ control chamber needed to close the control valve and $\lambda$ coefficient being the proportionality factor resulting from the media flow 
resistance executing the process have also a significant influence on the process of correct control chamber operation while closing the control valve (Roberson and Crowe, 1995). This dependence can be presented in the form of:

$$
v_{o}\left(L_{S}, D_{s}\right) \leq \lambda \frac{\pi L_{s} D_{S}^{2}+4 V_{S Z}}{4 A}
$$

After the experiment, the transport module model was disassembled, dried and then reaction chamber was filled with substance $B$, which was then covered with substance $A$. The prepared transport module model was used in further studies.

After filling tank 1 (glass tube) with water, the experiment was initiated. Valve 2 was closed and the upper lid was removed with a pressure gauge 5 and a valve 6 . Then, a transport module model was inserted vertically into tank 1 containing substances $A$ and $B$ in the reaction chamber. The behavior of the model is illustrated in Fig. 3a. At the beginning, through the openings in the bottom, water entered the working chamber causing the air (2) to push the float into the float and thus the control chamber, and then it emerged outside under the cap. The increase of the water level in the working chamber causes an increase in the average density of the transport module and the decrease in the buoyancy force. This leads to the module submergence. Then we close the upper lid of tank 1 . The surface tension in tube 1 and the too low pressure difference between the working and reaction chamber prevents water from entering the reaction chamber.
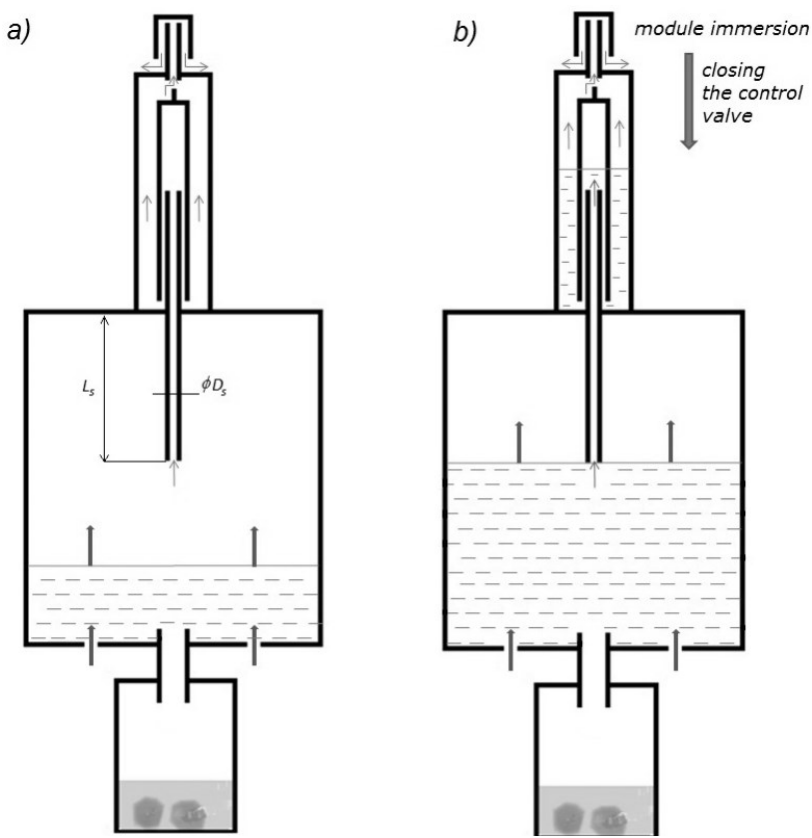

Fig. 3. a) The course of the initial stage of immersion process.

b) Illustration of module immersion with the start of closing the control valve

As immersion proceeds, the water level in the working chamber rises. This causes a continuous flow of air through tube 2, the float, the control chamber and through the socket. When the mirror reaches the water inlet to tube 2, the water level in the working chamber ceases to rise. However, water flows through tube 2 to the float and then to the control chamber. An air cushion forms in the float and the water displaces the rest of the air from the control chamber through the cap. As the water level in the control chamber increases, the buoyancy force on the float increases, causing it to move towards the closing of the control valve. This has been illustrated in Fig. $3 b$.

After filling the control chamber with water, the buoyancy force is big enough to cause the float to move upwards, closing the control valve. The correctness of this process guarantees fulfillment of relation (1). Because the transport module falls - since the water filling of the working chamber and the control chamber has led to an increase in the average density of the module to a value higher than the density of water - the pressure inside the working chamber 
increases. Once the desired immersion depth has been reached, the hydrostatic pressure reaches a value that enables the water inflowing process through water tube 1 into the reaction chamber to start.

The mechanism of this process is symbolically shown in Fig. 4. At the initial moment, the pressure inside the reaction chamber is approximately equal to the hydrostatic pressure prevailing in the working chamber at the entrance to tube 1 (Fig. 4a) and the water volume in tube $1 V_{r w}=0$. Let us assume that the volume of the reaction chamber is equal to the sum of the volume of the actual gaseous medium in the reaction chamber $V_{k k}$ and the volume of the gaseous medium in pipe $1 V_{k r}: V_{k}=V_{k k}+V_{k r}$.

The volumes of solid and liquid reactants (substances $A$ and $B$ ) in this consideration are not taken into account due to practical incompleteness in this case.

As the hydrostatic pressure increases, water flows into tube 1. The volume of water contained in tube $1\left(V_{r w}\right)$ is strictly conditioned by maintaining the pressure balance in the working chamber $\left(p_{h}\right)$ plus the hydrostatic pressure resulting from the filling of the tube to the height of $I$ $(y l)$ with the $p_{k}$ pressure prevailing in the reaction chamber, which increased due to the compression of the gaseous medium contained in the reaction chamber due to the gas volume being reduced by the volume $V_{r w}$ (Fig. 4b).

As $p_{h}$ pressure increases, tube 1 becomes completely filled with water. Then $V_{r w}=V_{k r}$, which causes $p_{k}$ pressure in the reaction chamber to increase. Then, with a further increase in $p_{h}$ pressure at the end of tube 1, a drop of water with a volume of $V_{k w}$ appears. The increase in the droplet volume causes that at some point the drop's weight is greater than the forces resulting from the surface tension (holding the drop at the end of tube 1) causing drop detachment, falling into substance $A$ and $B$ mixture (Fig. 4c). Subsequent drops fall into the substance $A$ and $B$ mixture.

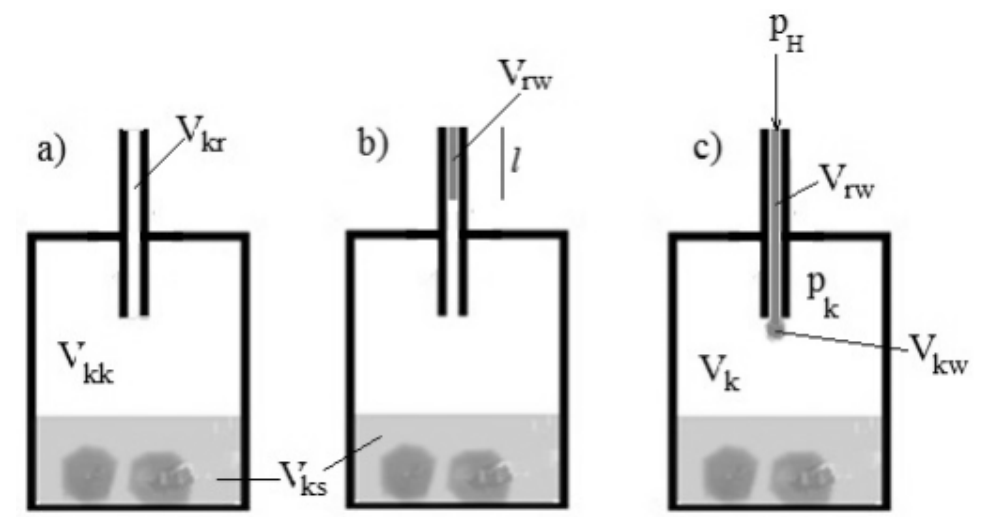

Fig. 4. Diagram of the operating mechanism of the reaction chamber.

The process of water penetration into the reaction chamber up to the initiation of the reaction of water with substance B can be represented in the form of a transformed van der Waals equation (Berry and Rice and Ross, 2000):

where:

$$
H=\frac{1}{g \rho_{w}}\left(\frac{n_{k} R T}{V_{k}-V_{r w}-V_{k w}-n_{k} b}-n_{k}^{2} \frac{a}{\left(V_{k}-V_{r w}-V_{k w}\right)^{2}}\right)-p_{o}
$$

$g$ - gravitational acceleration,

$\rho_{w}$ - water density,

$n_{k}$ - amount of moles of air in the reaction chamber,

$R$ - universal gas constant,

$T$ - air temperature in the reaction chamber,

$a, b$-coefficients of van der Waals equation for air,

$a=0.136 \mathrm{Jm}^{3} / \mathrm{mol}^{2}, b=3.6510^{-5} \mathrm{~m}^{3} / \mathrm{mol}$ (Mizerski, 2013)

$p_{o}$-atmospheric pressure above the water surface,

$V_{k}$ - air volume in the reaction chamber,

$V_{r w}$ - water volume in tube 1 , 
$V_{k w}$ - water volume entering the reaction chamber,

$H$ - immersion depth of the object.

Equation (2) can be transformed into a cubic equation, also known as the third degree equation, in which the volume of water entering the reaction chamber can be represented as a function of the depth of the immersed object $V_{k w}(H)$. Then you can determine analytically (eg., the Cardan formulas (Bronsztejn and Siemiendiajew, 2000) the sought value of $V_{k w}(H)$. The form of this equation can be symbolically represented in the following form:

$$
0=\alpha V_{w}^{3}+\beta V_{k w}^{2}+\gamma V_{k w}+\delta
$$

Because in this article we focused mainly on presenting the concept of construction and operation of an autonomous transport module and an experimental confirmation of the possibility of its use in seabed transport, we will not consider the solution of this equation in this article, directing the interested to our next article. From a mathematical point of view, "every cubic equation with real coefficients has at least one real root" (Bronsztejn and Siemiendiajew, 2000) and from the physical point of view it does not. And here there is a problem that should be clarified if this topic were to continue, which is not the subject of this study.

The transport module is immersed all the time until it reaches the bottom (the set depth). Finally, the water dissolved in substance A begins to react with substance B. Gas reaction products $-\mathrm{C}_{2} \mathrm{H}_{2}$ acetylene - start to separate. The pressure in the reaction chamber increases. After exceeding the pressure prevailing in the working chamber, equal to the external pressure prevailing at a given depth at the end of tube 1 from the working chamber side, gas bubbles appear - the product taking place in the reaction chamber. The gas bubbles released into the working chamber cause the water level in the working chamber to drop. This process is illustrated in Fig. 5a.
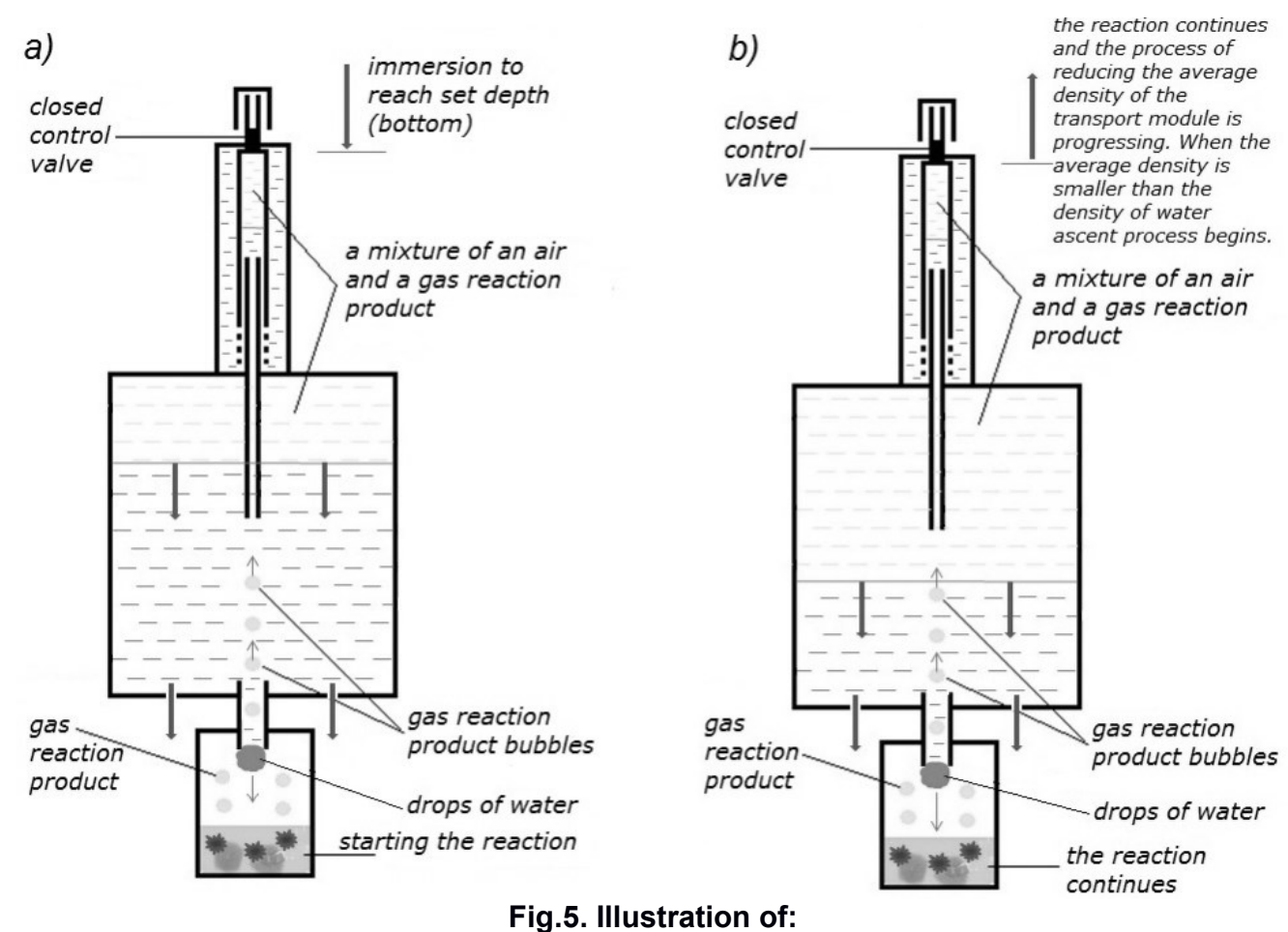

Fig.5. Illustration of:

a) module immersion with a closed control valve. b) the transport module ascent.

After reaching the set depth (bottom), the reaction continues to increase the pressure inside the module and causes further lowering of the water table in the working chamber by pushing it through the holes in its bottom. The control valve is always closed. The result is a continuous reduction of the average density of the transport module until reaching a density less than the surrounding water. At this moment the buoyancy force is greater than the weight of the transport module and the ascent process begins. This is illustrated in Fig. 5b. The direction of 
the drop of water which is the factor causing the reaction and the direction of the bubbles of the gaseous reaction product are marked on Fig. $5 \mathrm{~b}$.It should be noted that after the ascense process has begun, the process of decreasing the average density of the transport module proceeds much faster due to the decrease in external pressure and thus the expansion of gases in the reaction chamber and in the working chamber.

After emergence, the hub of the transport module is above the free surface of the surrounding water and emptying of the control chamber may occur. This process will occur if the pressure inside the working chamber falls below the hydrostatic pressure of the water weight in tube 2 . Water then flows through tube 2 from the control chamber to the working chamber by unblocking the control valve. After emptying the control chamber, the system returns to the "starting point". It should be remembered that the system will be immersed when this state is reached. Due to the fact that the energy source has been used for ascent - not stopping the immersion process, until the source of energy is replenished, will result in module sinking.

Fig. 6 presents one of a series of 14 experimental simulations of the operation of the transport module.

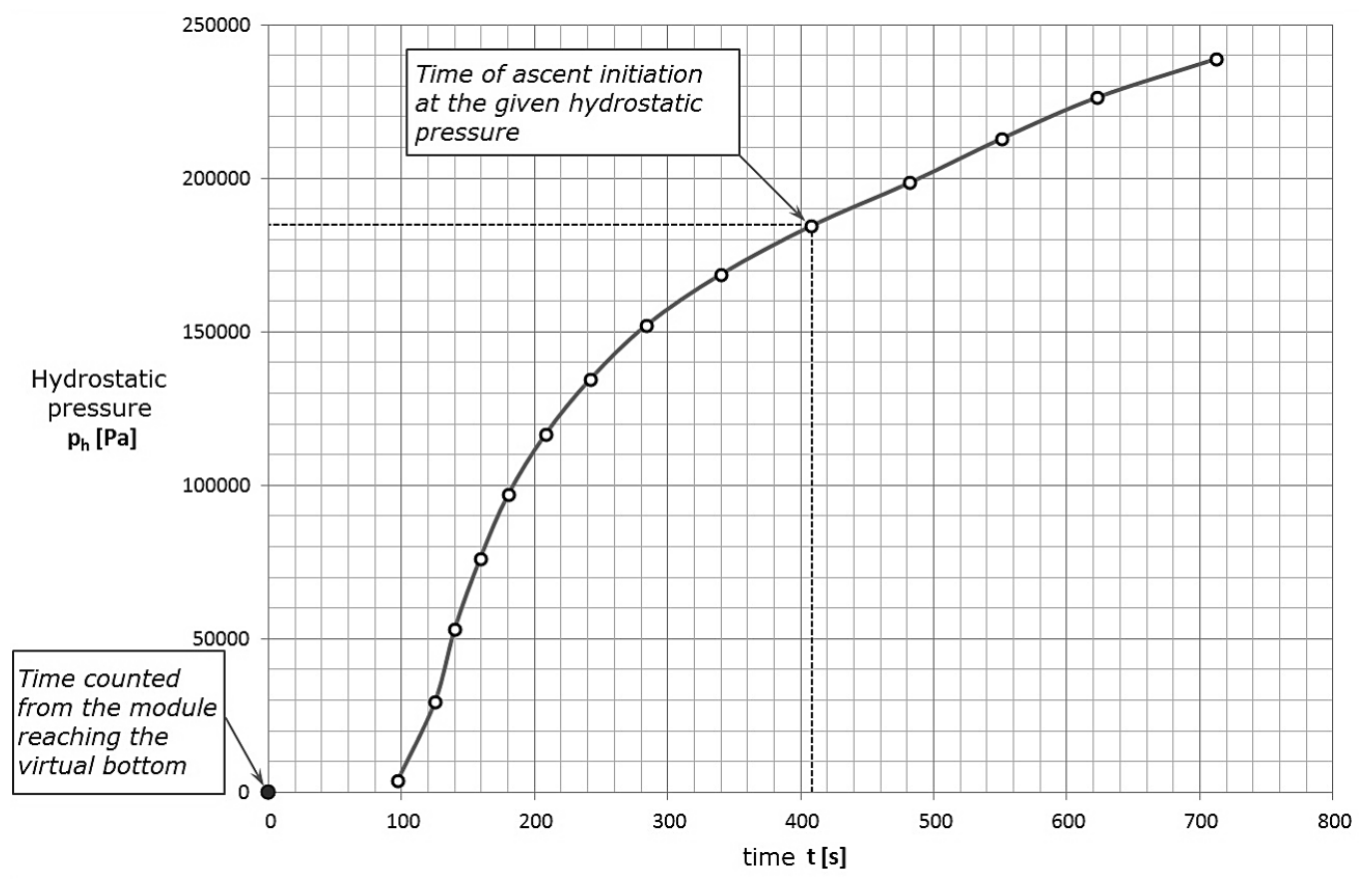

Fig. 6. Illustration of the experimental work process of the transport module.

At the start of the immersion process, the pressure was increased in a glass tube until the module reached the bottom of the measuring vessel. The increase of hydrostatic pressure in time was chosen so as to simulate the actual process of sinking to the bottom of the analyzed module. When it reached the bottom of the measuring vessel, the process of increasing the hydrostatic pressure was completed. From that moment we counted the time of the experiment, which is illustrated by the red point on the graph. As the pressure in the reaction chamber increased due to immersion, the water dropped into the reaction chamber in drops. In the reaction, one of the products was gas - acetylene. Its separation caused an increase in pressure in the reaction chamber and consequently its flow into the working chamber. This in turn caused the outflow of water from the working chamber through the openings to the outside. The result was an increase in buoyancy force and ascent of the module. Each subsequent ascent initiation at the given hydrostatic pressure - the depth of immersion, was plotted on the graph and illustrated with a graphic sign of the circle. As you can see, we managed to simulate the immersion and ascent process for a depth of $25 \mathrm{~m}$.

The volume of substance A used in this series of experiments was $500 \mu \mathrm{l}$ and the mass of substance B was $500 \mathrm{mg}$. We obtained very good repeatability of results, therefore we present 
only the most representative course of the experimental simulation of the transport module performance.

\section{CONCLUSIONS}

The experiments carried out confirm the possibility of using a transport module for transport from the seabed. The concept of the module's construction and the principles of its operation have been confirmed in experiments, which is well illustrated by the film documentation of their course. The transport module autonomously performed the operations planned for it: flooding the working chamber into the planned volume, flooding the control valve and closing it, reaching the planned immersion depth, and emerging from it, emptying the control chamber and working chamber after reaching full ascent.

By observing and analyzing the course of the experiments, we came to the conclusion that for the correct mathematical-physical description, the transport module should be treated as an inseparable whole. Initially, we tried to describe the phenomena occurring during the operation of the transport module for each of its basic three elements separately. The received relationships allowed us to describe the work of the element in a good way but did not allow to describe the operation of the transport module as a whole. The exact presentation of the method - due to its high complexity - will be presented in the next publication. The solution is based on a system of third degree equations.

The proposed and constructed test stand allowed us to verify the principle of operation and construction assumptions of the transport module to a pressure corresponding to a depth of 25 $\mathrm{m}$. However, according to the authors, based on the obtained results, it is possible to expect correct operation also at great depths. The power source used in the form of carbon acetylide (carbide) generated sufficient energy (even with a reserve) which can be seen from the shape of the curve on the graph (Fig. 6), characterized by a derivative different from zero at the end of the experiment. Therefore, we can successfully apply this method to pressures corresponding to much deeper depths. Unfortunately, chemical instability due to the reaction of acetylene is hindered. The matter of power sources is the subject of further research.

The experiments also show that it would be beneficial in real conditions to use a bundle of capillaries whose sum of cross-sectional areas corresponds to the planned cross-section of the working tube of the actual transport module. The use of such a bundle of capillaries will facilitate the use of surface tension and increased flow resistance to regulate the work of the module.

\section{ACKNOWLEDGMENTS}

This article was written within Statutes Research AGH, No. 11.11.100.005

\section{REFERENCES}

Berry R.S., Rice S.A., Ross J. (2000), Physical chemistry, Oxford University Press, pp 298-306

Bronsztejn I.N., Siemiendiajew K.A. (2000), Matematyka. Poradnik encyklopedyczny, Wydawnictwo Naukowe PWN, Warszawa.

Abramowski T., Kotliński R. (2011), Współczesne wyzwania eksploatacji oceanicznych kopalin polimetalicznych, Górnictwo i geoinżynieria, Rok 35, zeszyt 5, pp.41-61.

Depowski, S., Kotliński R., Rühle E., Szamałek K. (1998), Surowce mineralne mórz i oceanów, Wydawnictwo Naukowe Scholar, Warszawa.

Filipek W., Broda K. (2016), Theoretical foundation of the implementation of controlled pyrotechnical reactions as an energy source for transportation from the sea bed, Scientific Journals of the Maritime University of Szczecin, 48 (120), 117-124.

Filipek W., Broda K. (2017), The Theoretical Basis of the Concept of Using the Controlled Pyrotechnical Reaction Method as an Energy Source in Transportation from the Sea Bed, TransNav the International Journal on Marine Navigation and Safety of Sea Transportation, Vol.11, No. 4, 653-659.

http://www.nautilusminerals.com [12 March 2016]

Kaczyński J., Czaplicki A. (1977), Chemia ogólna, Wydawnictwo Naukowo-Techniczne, Warszawa.

Karlic S. (1984), Zarys górnictwa morskiego, Wydawnictwo „Śląsk”, Katowice 
Morrison R.T., Boyd R.N. (1997), Chemia organiczna, Wydawnictwo naukowe PWN, Warszawa

Roberson, J.A., Crowe, C.T. (1995). Engineering Fluid Mechanics. John Wiley \& Sons, Inc. Sharma, R. (2017), Deep-Sea Mining: Resource Potential, Technical and Environmental Considerations, Springer International Publishing AG, Cham

Sobota J. et. al. (2005), Systemy i technologie wydobycia konkrecji z dna oceanów. Zeszyty Naukowe Akademii Rolniczej we Wrocławiu nr 521, Monografie XLIII, Seria: Współczesne problemy inżynierii środowiska. Wrocław

SPC (2013), Deep Sea Minerals: Sea-Floor Massive Sulphides, a physical, biological, environmental, and technical review. Baker, E., and Beaudoin, Y. (Eds.) Vol. 1A, Secretariat of the Pacific Community, ISBN 978-82-7701-119-6, Available from: http://gsd.spc.int/dsm/public/files/meetings/ TrainingWorkshop4/UNEP_vol1A.pdf [12 July 2015]

Tuliszka E. (1980), Mechanika płynów. Warszawa: Państwowe Wydawnictwo Naukowe

Date of submission of the article to the Editor: 06/2018

Date of acceptance of the article by the Editor: 09/2018 